\title{
Bridging scales: from cortical single-neuron bursting to macroscopic high-frequency EEG
}

\author{
Bartosz Telenczuk*1, Stuart Baker ${ }^{2}$, Andreas Herz ${ }^{3}$ and Gabriel Curio ${ }^{1}$
}

\author{
Address: ${ }^{1}$ Neurologie, Charité Universitätsmedizin, Berlin, Germany, ${ }^{2}$ Institute of Neuroscience, Newcastle University, UK and ${ }^{3}$ Neurobiology \\ Department, Ludwig-Maximilians Universität, Munich, Germany \\ Email: Bartosz Telenczuk* - b.telenczuk@biologie.hu-berlin.de \\ * Corresponding author
}

from Eighteenth Annual Computational Neuroscience Meeting: CNS*2009

Berlin, Germany. 18-23 July 2009

Published: I 3 July 2009

BMC Neuroscience 2009, I0(Suppl I):P73 doi:I0.I |86/I47|-2202-I0-SI-P73

This abstract is available from: http://www.biomedcentral.com/I47I-2202/I0/SI/P73

(c) 2009 Telenczuk et al; licensee BioMed Central Ltd.

One of the challenges of neuroscience is to understand the relation between multiple levels of neuronal organization: from ion channels to single cells to local neuronal networks to the entire brain. In particular, the relation between single neurons and population activity has recently gained much interest. Combining experimental and modeling work, we investigate here how these two levels are related in a phenomenon called 'population bursting'. This term refers to short trains of action potentials that are synchronous over a large population of neurons and thus rendered visible in local and even far field potentials (LFP, EEG). Such responses were identified in many brain areas, among others in hippocampus and cortex. Here, we focus on bursts elicited by neurons in primary somatosensory cortex after peripheral nerve stimulation. We show that these single-unit bursts are closely related to high-frequency EEG responses (hf-EEG $>500 \mathrm{~Hz}$ ) recorded from scalp or dura in both, human subjects and non-human primates $[1,2]$. In order to understand the mechanisms of burst generation, we developed a simple single-neuron model that reproduces burst activity and provides a means for estimating the contribution of a single neuron to the macroscopic EEG. The model consists of a linear neuron with spiking threshold (leaky integrate-and-fire) that receives conductance-based inputs through depressing synapses (short-term synaptic depression). The inputs to the neuron are provided by a population of Poisson neurons all firing at a constant rate.
We fitted the model to spike trains recorded in the somatosensory cortex of non-human primates and found that the subthreshold potential produced by the neuron resembles the time-course of evoked hf-EEG oscillations (Figure 1). This suggests that the hf-EEG might give access to the microscopic properties of neural systems, such as synaptic and neuronal time constants, thus bridging the gap between single-neuron dynamics and macroscopic population response.

\section{Acknowledgements}

This work was supported by SFB 618 "Theoretical Biology" (Project B4) and Wellcome Trust.

\section{References}

I. Curio G, Mackert BM, Burghoff M, Koetitz R, Abraham-Fuchs K, Härer W: Localization of evoked neuromagnetic $600 \mathrm{~Hz}$ activity in the cerebral somatosensory system. Electroencephalogr Clin Neurophysiol 1994, 9 I:483-487.

2. Baker S, Curio G, Lemon R: EEG oscillations at $600 \mathrm{~Hz}$ are macroscopic markers for cortical spike bursts. J Physiol 2003, 550:529-534. 

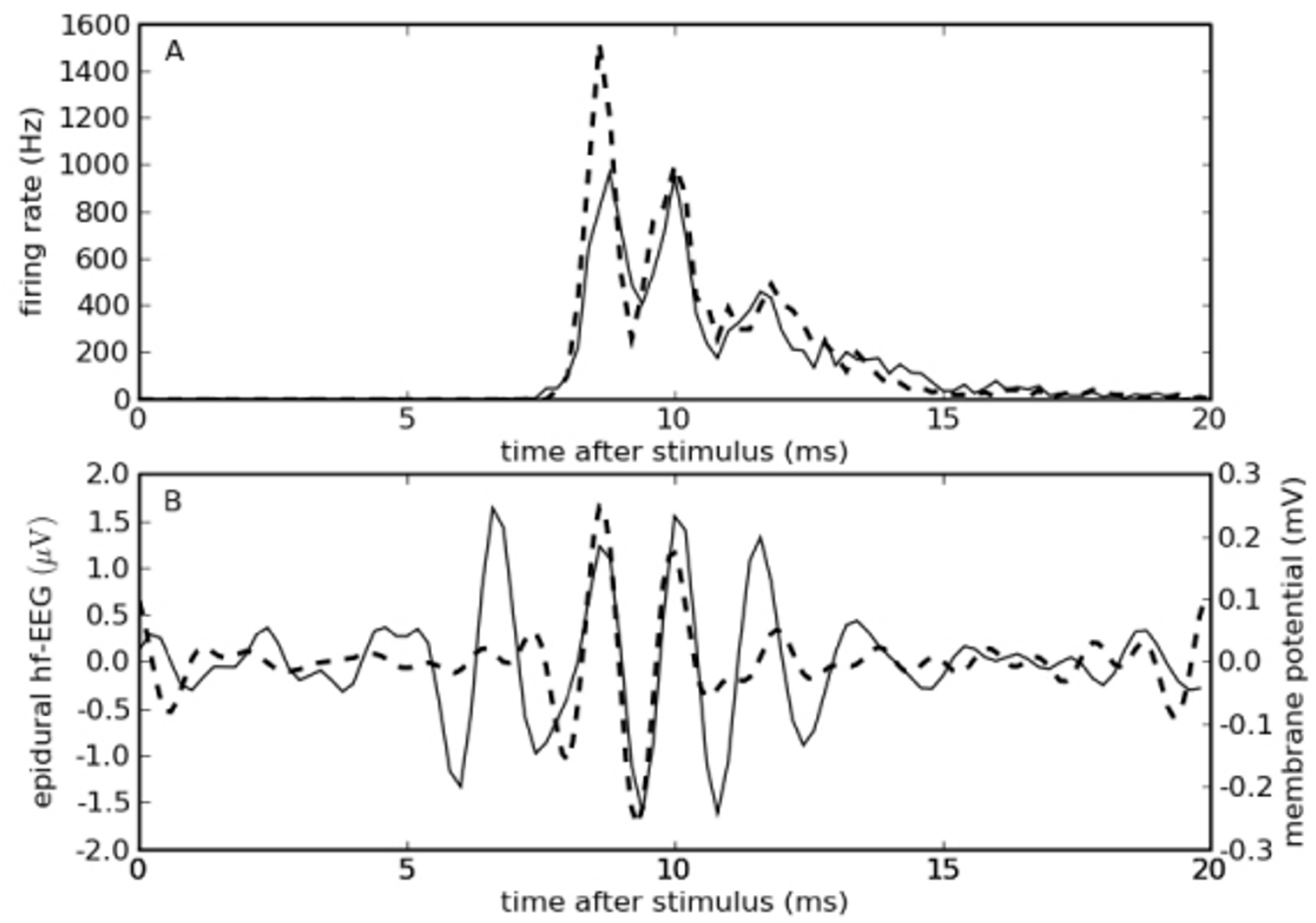

\section{Figure I}

Modeling population bursts in SI cortex of macaques. (A) The post-stimulus time histogram (PSTH, bin width 0.2 ms) of spikes elicited in a single neuron by an electrical stimulation of the median nerve (solid line) is well reproduced in a model neuron (dashed line). (B) Average subthreshold membrane potential recorded from the model (dashed line) aligns with several peaks of evoked hf-EEG response (average of 956 trials); both traces band-pass filtered $(400-1200 \mathrm{~Hz})$.

\begin{tabular}{|} 
Publish with Biomed Central and every \\
scientist can read your work free of charge \\
"BioMed Central will be the most significant development for \\
disseminating the results of biomedical research in our lifetime. " \\
Sir Paul Nurse, Cancer Research UK \\
Your research papers will be: \\
• available free of charge to the entire biomedical community \\
• peer reviewed and published immediately upon acceptance \\
• cited in PubMed and archived on PubMed Central \\
• yours - you keep the copyright \\
Submit your manuscript here: \\
http://www.biomedcentral.com/info/publishing_adv.asp
\end{tabular}

